\title{
Simulated reduction in Atlantic hurricane frequency under twenty-first-century warming conditions
}

\author{
THOMAS R. KNUTSON*, JOSEPH J. SIRUTIS, STEPHEN T. GARNER, GABRIEL A. VECCHI \\ AND ISAAC M. HELD
}

NOAA/Geophysical Fluid Dynamics Laboratory, Princeton, New Jersey 08542, USA

*e-mail: Tom.Knutson@noaa.gov

Increasing sea surface temperatures in the tropical Atlantic Ocean and measures of Atlantic hurricane activity have been reported to be strongly correlated since at least 1950 (refs 1-5), raising concerns that future greenhouse-gas-induced warming ${ }^{6}$ could lead to pronounced increases in hurricane activity. Models that explicitly simulate hurricanes are needed to study the influence of warming ocean temperatures on Atlantic hurricane activity, complementing empirical approaches. Our regional climate model of the Atlantic basin reproduces the observed rise in hurricane counts between 1980 and 2006, along with much of the interannual variability, when forced with observed sea surface temperatures and atmospheric conditions ${ }^{7}$. Here we assess, in our model system ${ }^{7}$, the changes in large-scale climate that are projected to occur by the end of the twenty-first century by an ensemble of global climate models ${ }^{8}$, and find that Atlantic hurricane and tropical storm frequencies are reduced. At the same time, near-storm rainfall rates increase substantially. Our results do not support the notion of large increasing trends in either tropical storm or hurricane frequency driven by increases in atmospheric greenhouse-gas concentrations.

Tropical Atlantic sea surface temperatures (SSTs) have increased over the past century ${ }^{3,9,10}$, and anthropogenic forcing has probably contributed to this warming ${ }^{9,10}$. There is little question that Atlantic hurricane counts and the power dissipation index (PDI, a measure of the destructive potential of storms) have increased markedly since 1980, along with a recent increase in Atlantic SSTs (refs 4,5). Looking further back in time, observational analyses have produced intriguing but often conflicting results, depending in part on details of the adjustments for storm undercounts or intensity biases in the pre-satellite era ${ }^{4,11-15}$. Some investigators have concluded that past greenhouse warming caused a substantial rise in Atlantic tropical storms and hurricanes during the twentieth century $y^{3,5}$. It has been argued that the Atlantic PDI in the past decade has reached high levels (unprecedented since $\sim 1950$ ) and that it correlates well with low-frequency tropical Atlantic SST variations from 1950 to the present. Given the much more pronounced Atlantic warming projected for the twenty-first century ${ }^{6,8}$, extrapolation of these reported relationships would suggest a very large future increase in Atlantic hurricane frequency and PDI.

Dynamical models bring important extra perspectives to this question. We have developed a new regional modelling framework ${ }^{7}$ designed specifically for downscaling Atlantic hurricane activity.
For the present-day simulations, the model uses observed SSTs, and the interior solution is nudged towards observed atmospheric reanalyes ${ }^{16}$ on large spatial scales (see the Methods section) for each August-October season from 1980 to 2006. Hurricanes develop from weak disturbances that are generated spontaneously by the model, in ways that are dependent on the large-scale environment. To demonstrate the model's hurricane simulation skill, Fig. 1a shows simulations obtained using two slightly different versions of the model (referred to here as Model1 and Model2) ${ }^{7}$. Model2 is our control for the climate warming experiments described below. The year-to-year variability in Atlantic hurricane counts (1980-2006) is well reproduced by the model ensemble mean $(r=0.84)$, as well as by Model 1 and Model 2 individually ${ }^{7}$. El Niño-related interannual variations in hurricane activity are also well reproduced ${ }^{7}$. The model simulates an increase in hurricane counts (1980-2006), although the simulated trend is $\sim 40 \%$ larger than the observed increase (Fig. 1a).

A limitation of the model is that it does not simulate hurricanes as intense as observed (Fig. 1b, Supplementary Information, Fig. S1). Minimum central pressures of $\sim 937 \mathrm{hPa}$ and maximum surface winds of $\sim 47 \mathrm{~m} \mathrm{~s}^{-1}$ are the most intense simulated in the control, compared with $882 \mathrm{hPa}$ and $\sim 85 \mathrm{~m} \mathrm{~s}^{-1}$ maximum intensities in observations. Thus, model simulations of indices that are strongly influenced by intense hurricanes (such as PDI) should be treated with caution. The ensemble model produces an increasing trend in PDI (1980-2005) $)^{7}$, although it is 25\% smaller than the observed increase. For major hurricanes (using the central pressure criterion of $<965 \mathrm{hPa}$ (ref. 7)), both the mean number and increasing trend (1980-2005) in the model are about half as large as observed, although the model's variability correlates well $(r=0.7)$ with observations ${ }^{7}$.

Storm trajectories for contrasting active and inactive seasons (Fig. 2a-d) further illustrate the control model's performance. The truncated tracks near the northern boundary of the model domain are an artefact of the boundary nudging. Animated fields from sample seasons are available in the Supplementary Information.

We use Model2 to explore the influence of future climate warming on Atlantic hurricane activity. We re-run each August-October season (1980-2006), keeping the daily to multidecadal variations unchanged, but altering the August-October mean atmospheric state (used by the interior nudging) and SSTs according to late twenty-first-century changes 


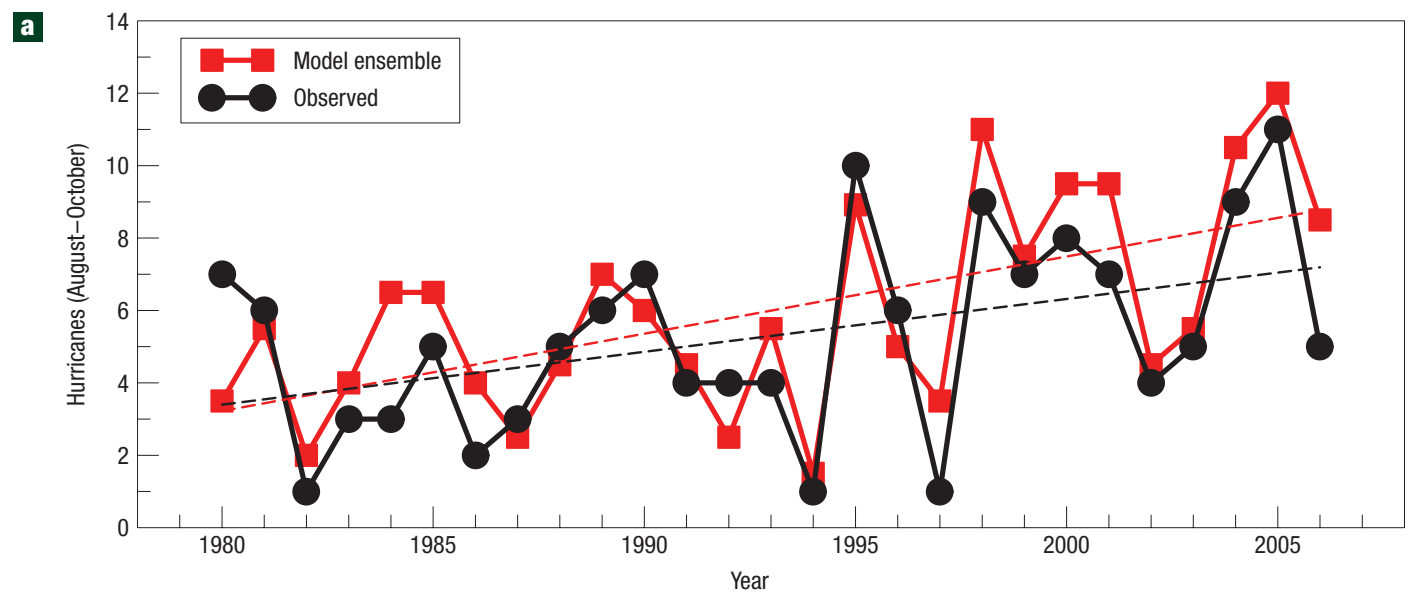

b

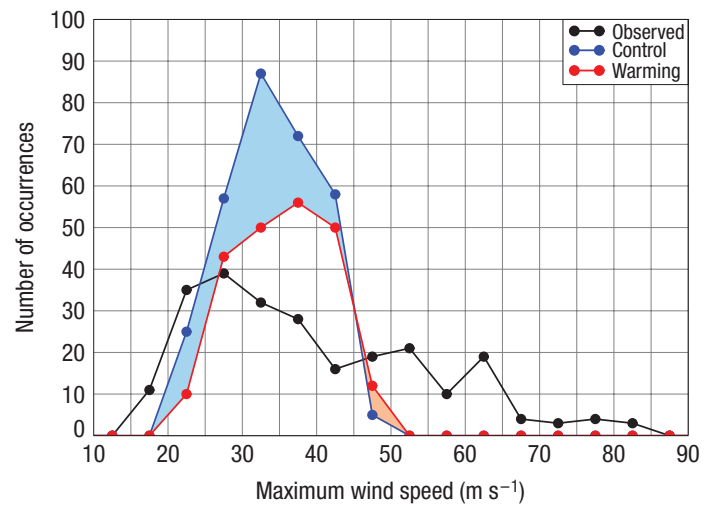

G

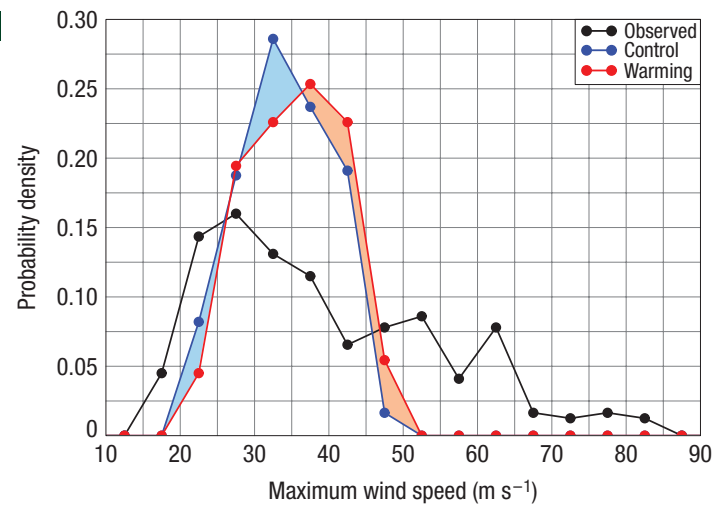

Figure 1 Model versus observed Atlantic hurricane counts and distributions of maximum tropical cyclone wind speeds. a, Annual (August-0ctober) counts of Atlantic hurricanes in observations and for the model using observed SSTs and large-scale nudging of the interior solution towards reanalyses. Correlation $=0.84$; linear

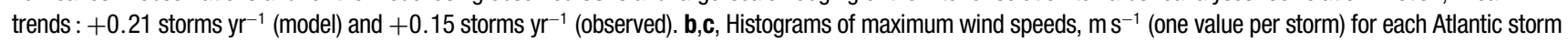
observed or simulated by the model for 1980-2006 (August-0ctober). The normalized histogram (c) was obtained by dividing by the total number of storms observed or simulated during the $27 \mathrm{yr}$ period. This controls for differences in storm frequency between experiments or between the control and observations.

simulated by a multimember ensemble of the World Climate Research Program Coupled Model Intercomparison Project 3 (CMIP3) models ${ }^{8,17}$ under Intergovernmental Panel on Climate Change (IPCC) emissions scenario A1B (ref. 6) (see the Methods section). The projected climate state has warmer tropical Atlantic SSTs (by $1.72{ }^{\circ} \mathrm{C}$, see Supplementary Information, Fig. S2a), enhanced upper-tropospheric warming relative to the surface (see Supplementary Information, Fig. S2b) and enhanced vertical wind shear and reduced low- to mid-tropospheric relative humidity across the Caribbean ${ }^{17}$.

In the warm-climate runs, our model generates substantially fewer tropical storms $(-27 \%)$ and hurricanes (-18\%) (Fig. 3, Supplementary Information, Fig. S3). Comparing 27 warm-climate seasons with the control, 22 years have a decrease in tropical storms, 3 have an increase and 2 show no change. Major hurricane counts decrease by $8 \%$. Thus, the reduction in numbers is most pronounced for weaker storms. Storm tracks for the warming and control climates, as well as observed, are shown in Fig. 2 and Supplementary Information, Fig. S4 (the latter for each individual year). Dynamical reasons for the reduced storm frequency remain under investigation. Preliminary sensitivity experiments indicate that the projected combined change in tropical SST and atmospheric lapse rate is not the primary driver.
Environmental changes in circulation and/or moisture are more likely the dominant factors in reducing storm frequency.

In agreement with previous studies ${ }^{18-21}$, the frequency and intensity of the strongest hurricanes simulated by the model are increased for both surface wind speed (Fig. 1b,c) and central pressure (see Supplementary Information, Fig. S5). More than twice as many hurricanes occur with wind speeds exceeding $45 \mathrm{~m} \mathrm{~s}^{-1}$ in the warm-climate runs (twelve versus five). The normalized frequency distributions (Fig. 1c) show, for the warm climate, an increased relative occurrence rate for all storm intensity categories above $35 \mathrm{~m} \mathrm{~s}^{-1}$. The mean maximum wind speed increases slightly, $(+2.9 \%)$ for tropical storms and hurricanes combined and by $1.7 \%$ for hurricanes alone. However, simulated PDI decreases by about 25\% (see Supplementary Information, Fig. S3f), owing to the decrease in tropical storm and hurricane frequency. As both the frequency of major hurricanes (see Supplementary Information, Fig. S3g) and the maximum intensities of the strongest hurricanes (Fig. 1b) are under-predicted in the control $\operatorname{model}^{7}$, results related to the most intense simulated storms should be regarded as only suggestive.

Near-hurricane rainfall rates (see Supplementary Information, Fig. S6), averaged over all hurricane periods, increase by $(37,23,10) \%$ when averaged within $(50,100,400) \mathrm{km}$ of the storm 

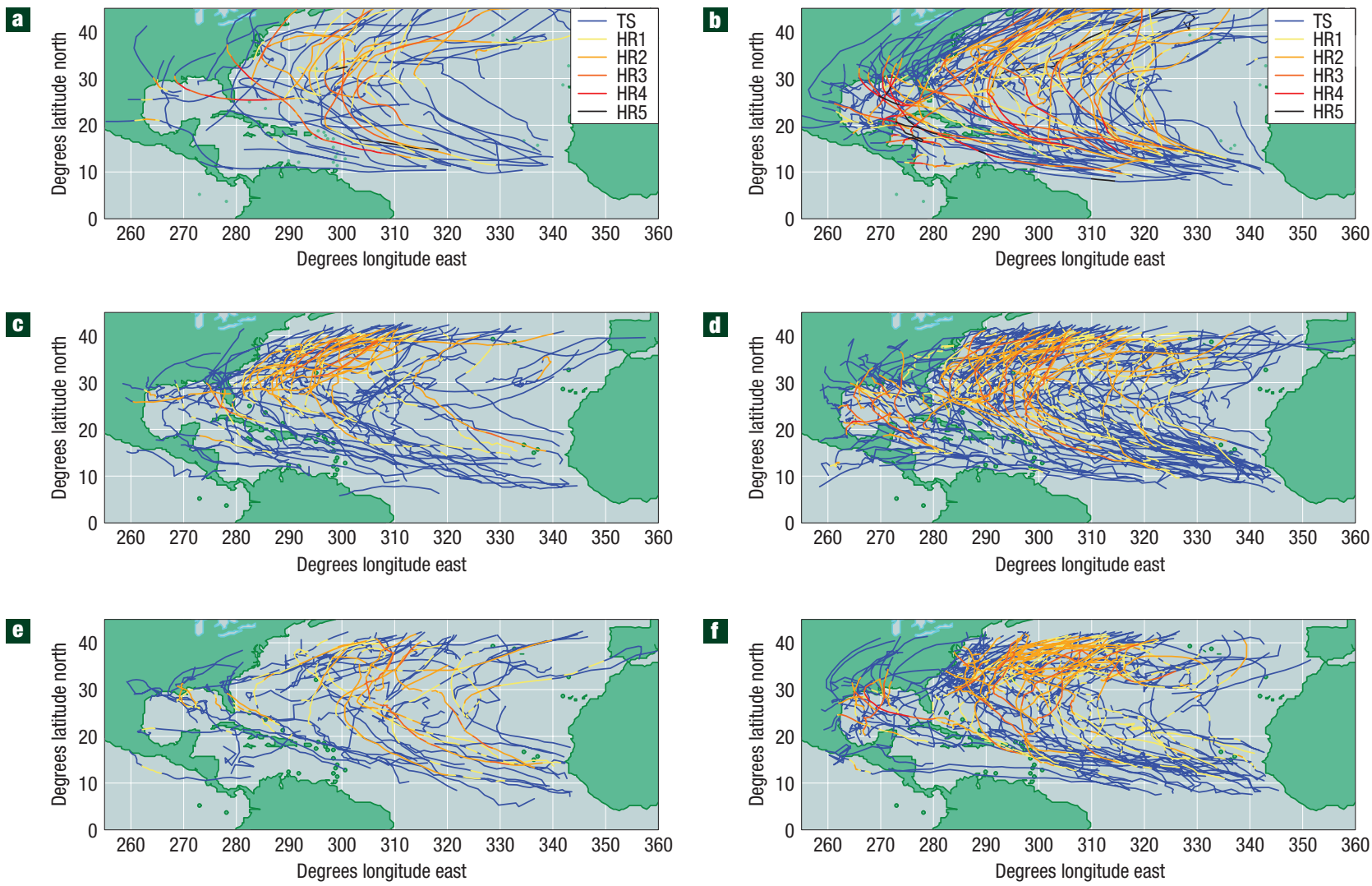

Figure 2 Tropical storm/hurricane tracks (observed and simulated) for the ten least and most active years. a-f, Active (a,c,e) or inactive (b,d,f) years are based on observed tropical storm counts during 1980-2006. The colour along the track denotes storm intensity, with Saffir-Simpson Category 2-5 intensity levels for hurricanes based on central pressure criteria. a,b shows observed storms ( 52 and 130 storms, respectively), c,d shows the control storms ( 82 and 145 storms, respectively) and e,f shows the warm-climate storms (58 and 109 storms, respectively). TS: tropical storms; HR1-5: Saffir-Simpson category 1-5 hurricanes.

centre. This is in reasonable quantitative agreement with a previous hurricane modelling study ${ }^{22}$. A caveat is that there is some evidence (see Supplementary Information, Fig. S6) that the control model's composite hurricane precipitation rates are higher than observed ${ }^{23}$.

As in previous studies, there is no indication that the region of Atlantic tropical storm formation expands with greenhouse warming (see Supplementary Information, Fig. S7). Storms typically develop in the control simulation, and in observations, over SSTs in excess of a 'threshold' temperature of about $26^{\circ} \mathrm{C}$. In the warmer climate, given the relatively homogeneous tropical warming, the 'threshold' temperature for storm formation increases in the model by the same amount as the mean tropical SSTs (Fig. 4d,e). Consequently, no pronounced expansion of the tropical storm formation region is simulated. This 'threshold' temperature for cyclone formation is clearly climate dependent, and is closely related to the temperature needed for a saturated parcel near the surface to be sufficiently buoyant to rise to the tropical tropopause.

The decrease in hurricane and tropical storm occurrence is slightly more evident in the western than eastern half of the basin (see Supplementary Information, Fig. S7). This is qualitatively similar to occurrence trend patterns since the late 1800 s in a recent tropical storm reconstruction ${ }^{15}$. Consequently, the simulated number of landfalling hurricanes decreases by more than the hurricane count itself (about 30\% versus 18\%; Supplementary Information, Fig. S3). We note that the band of increased vertical shear and decreased mid-tropospheric relative humidity stretching across the Caribbean in the multimodel ensemble projections ${ }^{17}$ should suppress activity more in the western half of the basin than in the east. As the detailed spatial pattern of shear and humidity change differs among the CMIP3 models ${ }^{17}$, this result may not be robust.

Uncertainties in the large-scale climate projections will translate into uncertainties in the downscaled tropical storm projections in ways that have not yet been quantified. Here, we use only the timemean changes projected by the CMIP3 climate models. We assume that changes in the time-mean state are the dominant control over tropical cyclone formation and that the CMIP3 ensemble mean provides the best available projection of these changes. Any simulated changes in atmospheric variability from the CMIP3 models are neglected, but our confidence in such changes obtained using current models is low.

Further simulations are underway with our downscaling model using mean climate changes generated by individual CMIP3 models rather than the ensemble mean across the models. Preliminary results suggest that the spread in hurricane activity projections obtained using individual models will be substantial (as also suggested in a recent study using a different modelling strategy ${ }^{24}$ ). As an initial example, we used the mean climate change from one model (GFDL CM2.1) that we expected would be more favourable than the ensemble mean for increased hurricane activity, on the basis of changes in large-scale shear over the Atlantic. A sample of 13 simulated seasons shows relatively little change in tropical storm $(-8 \%)$ or hurricane counts $(+7 \%)$, but a relatively large 
a

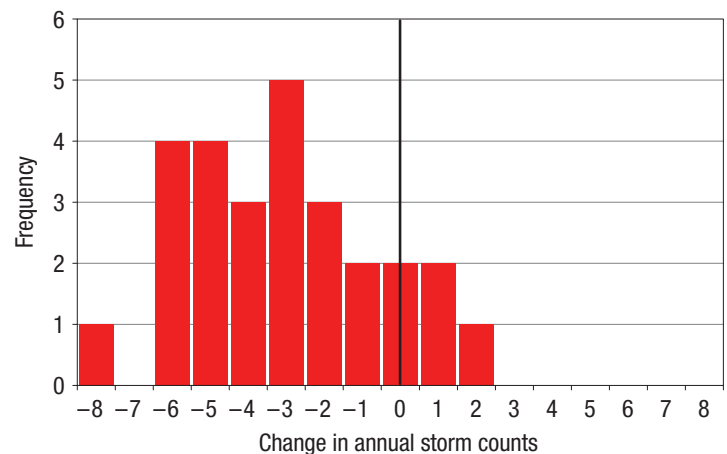

b

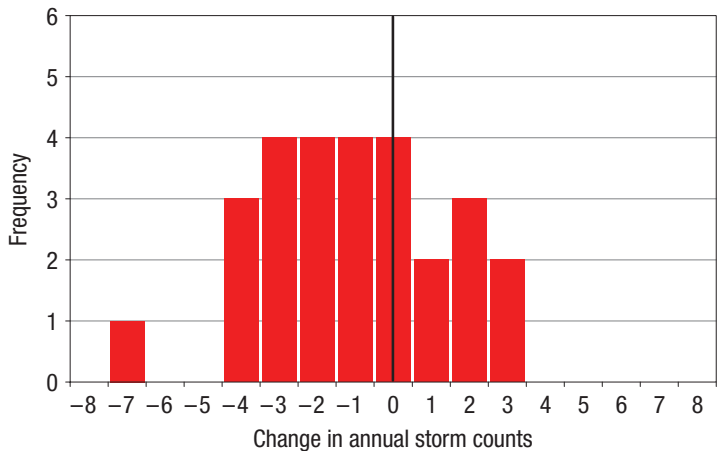

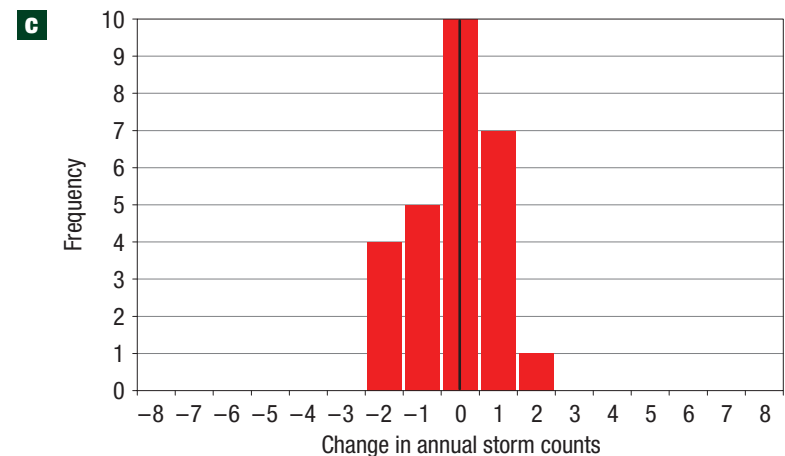

Figure 3 Frequency distribution of change (warm climate minus control) in storm counts for each year simulated. a-c, Distributions for Atlantic basin tropical storms (a), hurricanes (b) and major hurricanes (central pressures less than $965 \mathrm{hPa}$ ) (c). In the multimodel ensemble climate change experiments, tropical storm counts decrease by $27 \%$, hurricanes by $18 \%$ and major hurricanes by $8 \%$ relative to the control.

a

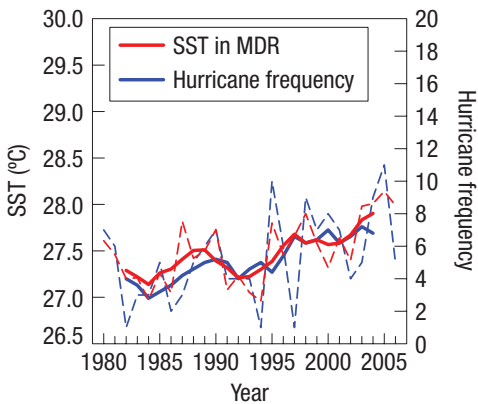

d

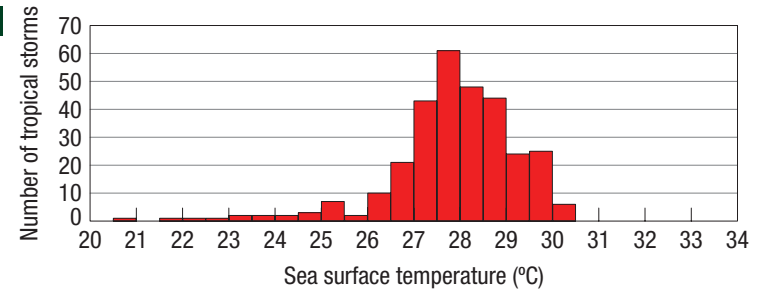

b

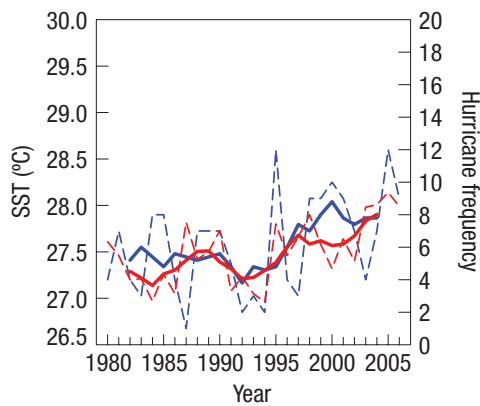

G

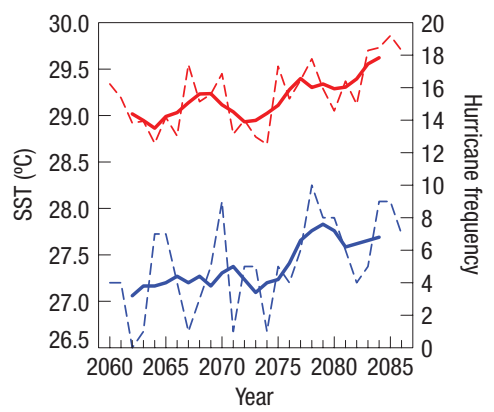

$\mathbf{\theta}$

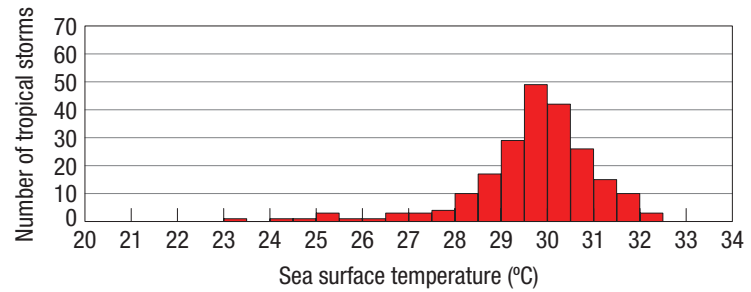

Figure 4 Tropical storm/hurricane counts versus SSTs for the control and warm-climate runs. a-c, Time series of Atlantic hurricane counts compared with main development region (MDR) SSTs during the 27 yr study period, for observations (a) and for the control (b) and warm-climate (c) simulations. Dashed lines are annual values (August- 0 ctober) and solid lines are $5 \mathrm{yr}$ running means of the August-0ctober values. The main development region here is $20^{\circ}-80^{\circ} \mathrm{W}, 10^{\circ}-20^{\circ} \mathrm{N}$. d,e, The tropical storm genesis events sorted by local SST levels for the control (d) and warm-climate (e) experiments.

increase $(\sim+70 \%)$ in major hurricane counts. This sensitivity of the hurricane response to details of the climate model projections highlights the need to better constrain regional climate responses to increased $\mathrm{CO}_{2}$.
A key limitation of our regional downscaling model is that it does not simulate the most intense hurricanes or the strong dependence of upper-limit intensities on SST observed in the present climate (see Supplementary Information, Fig. S1). Owing 
to these limitations, it is plausible that the model's quantitative projections of increased intensity and increased numbers of the most intense storms with climate warming are underestimates. Follow-on studies are underway with models capable of simulating higher-intensity hurricanes.

Our results using the ensemble-mean global model projections (Fig. 4) are inconsistent with the notion of large, upward trends in tropical storm and hurricane frequency over the twentieth century, driven by greenhouse warming ${ }^{3,5}$. The twentieth-century warming attributed to greenhouse gases by global models is sufficiently similar in spatial structure to the twenty-first-century projections used here that we are confident that our model's downscaled storm response to twentieth-century greenhouse warming would also be qualitatively similar to the results presented here. However, the general issue of twentieth-century attribution is made more complex by other radiative forcing changes (for example, aerosols, stratospheric ozone) that have no direct counterparts in the twentyfirst-century A1B scenario.

These results do not conflict with the hypothesis that low-frequency variability of Atlantic hurricane activity is largely controlled by SSTs, but they do disagree with the idea that these variations are primarily determined by local tropical Atlantic SSTs alone. When the North Atlantic warms more rapidly than other ocean basins, as it has since 1980, the changing SST gradients favour northward displacement of the Atlantic Intertropical Convergence Zone, and-in the main development region for Atlantic storms-reduced vertical shear ${ }^{25,26}$, reduced stability of the tropospheric thermodynamic profile $e^{27,28}$ and increased potential intensity ${ }^{29}$. Although the relative importance of these factors is unclear, they all favour tropical storm genesis, and probably produce the positive correlation between Atlantic SST and hurricane frequency in both observations and our model (Fig. 4a,b). The observed correlation between the Atlantic basin PDI and the difference between local tropical Atlantic SSTs and tropical mean $\mathrm{SSTs}^{30}$ also supports this interpretation. However, during the twenty-first century, tropical North Atlantic SSTs are not projected to warm more rapidly than other tropical regions according to the ensemble of CMIP3 models $^{29}$, implying conditions that do not favour increased tropical storm genesis.

In summary, our model supports the hypothesis that the primary driver of the recent increase in Atlantic hurricane numbers was the warming of the tropical Atlantic relative to the other tropical basins, rather than local increases in tropical Atlantic SSTs alone. The decrease in Atlantic tropical storm and hurricane frequency simulated by our model - in response to a pronounced twenty-first-century greenhouse warming-is markedly different from the large increase in future hurricane activity that might be projected using statistical analysis based only on the recent covariability of hurricanes and local SSTs.

\section{METHODS}

This study uses a regional atmospheric modelling framework designed specifically for dynamically downscaling Atlantic hurricane activity ${ }^{7}$. The non-hydrostatic model has a grid spacing of $18 \mathrm{~km}$ and is run without a subgrid-scale moist convective parameterization. The model is forced at the lower boundary by observed SSTs, and is relaxed at its horizontal boundaries, on a timescale of $3 \mathrm{~h}$, to agree with the time-evolving atmospheric state estimated by the National Centers for Environmental Prediction/National Center for Atmospheric Research reanalysis ${ }^{16}$. We also Fourier analyse the time-evolving reanalysis in the domain interior and relax the model $(36 \mathrm{~h}$ timescale) on the largest scales (basin wavenumbers 0-2) to these observed atmospheric conditions, including the winds, temperatures and relative humidity at all levels. The strength of the interior large-scale relaxation is the sole explicit tuning parameter in the model. This tuning, along with other details of the model design, is described in ref. 7. This parameter has the same value in every seasonal simulation and in both the control and warm-climate integrations.

Our evaluations of the model $l^{7}$ thus far have focused mostly on hurricane metrics, including hurricane precipitation. Many other metrics, such as the general space-time characteristics of the model's tropical convection, apart from seasonal-mean precipitation ${ }^{7}$, have not been evaluated in detail.

For our climate change experiment, we re-run each August-October season (1980-2006), relaxing towards a new solution consisting of the original observed conditions altered by a time-invariant three-dimensional climate change perturbation. This procedure keeps unchanged the largescale interannual to multidecadal variations in the interior as well as the high-frequency weather variability imposed at the model boundaries. The time-invariant climate change is the average change simulated by a multimodel ensemble of CMIP3 models ${ }^{8}$ used in the IPCC Fourth Assessment Report ${ }^{6}$ (years 2080-2099, A1B emission scenario). This method avoids some difficulties in the direct use of climate model simulations, which have known biases that can distort tropical storm simulations. We use the multimodel ensemble rather than separately downscaling each climate model, the latter being computationally prohibitive. The method assumes that the average downscaled hurricane response of the models can be approximated through downscaling the average climate change from the models. It further assumes that the atmospheric variability in the large (interior) scales and boundary conditions of our control simulation is also representative of conditions under the global warming scenario.

Using a multimodel ensemble to estimate the climate change perturbation also helps distinguish the models' radiatively forced response from model internal variability, which can be particularly pronounced in the Atlantic basin. In summary, our method simultaneously reduces possible contamination by internal climate variability, while also leveraging the benefits of ensemble averaging across climate models with different physics, tunings and parameterizations.

An important research question is whether hurricanes are able to maintain their intensities longer as they travel into higher latitudes in a warmer climate. Unfortunately, the placement of the model's northern boundary prevents us from addressing this issue.

In addition, as our simulations are restricted to the core of the Atlantic hurricane season (August-October), we do not address whether climate warming will change the season length by altering pre-August or post-October storms.

Although we originally intended to use the 18-model ensemble described in ref. 17 as our multimodel ensemble, owing to technical problems, we used a 14-model average to form the relative humidity perturbation, a 17-model average for atmospheric temperatures and winds and all 18 models of ref. 17 for SSTs. The difference between the full 18-model ensemble and the ensemble mean fields we used in our climate change runs is a very small fraction of the standard deviation of the 18-model estimates. It is extremely unlikely that a set of runs using means over all 18 models could be statistically distinguished from those reported here. The primary source of uncertainty in our climate perturbations is the uncertainty in the climate model projections themselves, rather than the precise set of models used to define our multimodel ensemble climate perturbation.

Received 1 February 2008; accepted 22 April 2008; published 18 May 2008.

References

1. Emanuel, K. A. Increasing destructiveness of tropical cyclones over the past 30 years. Nature 436, 686-688 (2005)

2. Webster, P. J., Holland, G. J., Curry, J. A. \& Chang, H.-R. Changes in tropical cyclone number, duration, and intensity in a warming environment. Science 309, 1844-1846 (2005).

3. Mann, M. \& Emanuel, K. Atlantic hurricane trends linked to climate change. Eos 87, 233-241 (2006).

4. Emanuel, K. Environmental factors affecting tropical cyclone power dissipation. J. Clim. 20, 5497-5509 (2007)

5. Holland, G. J. \& Webster, P. J. Heightened tropical cyclone activity in the North Atlantic: natural variability or climate trend? Phil. Trans. R. Soc. A, doi:10.1098/rsta.2007.2083 (2007).

6. Climate Change 2007: The Physical Science Basis—Contribution of Working Group I to the Fourth Assessment Report of the Intergovernmental Panel on Climate Change (eds Solomon, S. et al.) (Cambridge Univ. Press, Cambridge, 2007).

7. Knutson, T. R., Sirutis, J. J., Garner, S. T., Held, I. M. \& Tuleya, R. E. Simulation of the recent multidecadal increase of Atlantic hurricane activity using an 18-km-grid regional model. Bull. Am. Meteorol. Soc. 88, 1549-1565 (2007).

8. Meehl, G. A. et al. The WCRP CMIP3 multimodel dataset: A new era in climate change research. Bull. Am. Meteorol. Soc. 88, 1383-1394 (2007).

9. Knutson, T. R. et al. Assessment of twentieth-century regional surface temperature trends using the GFDL CM2 coupled models. J. Clim. 19, 1624-1651 (2006).

10. Santer, B. D. et al. Forced and unforced ocean temperature changes in Atlantic and Pacific tropical cyclogenesis regions. Proc. Natl Acad. Sci. 103, 13905-13910 (2006). 
11. Landsea, C. W. Hurricanes and global warming. Nature 438, doi:10.1038/nature04477 (2005)

12. Landsea, C. W. Counting Atlantic tropical cyclones back to 1900. Eos 88, 197, 202 (2007).

13. Chang, E. K. M. \& Guo, Y. Is the number of North Atlantic tropical cyclones significantly underestimated prior to the availability of satellite observations? Geophys. Res. Lett. 34 , L14801 (2007).

14. Mann, M. E., Sabbatelli, T. A. \& Neu, U. Evidence for a modest undercount bias in early historical Atlantic tropical cyclone counts. Geophys. Res. Lett. 34, L22707 (2007).

15. Vecchi, G. A. \& Knutson, T. R. On estimates of historical North Atlantic tropical cyclone activity. J. Clim. (2008, in the press)

16. Kalnay, E. et al. The NCEP/NCAR 40-year reanalysis project. Bull. Am. Meteorol. Soc. 77, 437-477 (1996).

17. Vecchi, G. A. \& Soden, B. J. Increased tropical Atlantic wind shear in model projections of global warming. Geophys. Res. Lett. 34, L08702 (2007).

18. Emanuel, K. A. The dependence of hurricane intensity on climate. Nature 326, 483-485 (1987).

19. Knutson, T. R., Tuleya, R. E., Shen, W. \& Ginis, I. Impact of $\mathrm{CO}_{2}$-induced warming on hurricane intensities as simulated in a hurricane model with ocean coupling. J. Clim. 14, 2458-2468 (2001).

20. Knutson, T. R. \& Tuleya, R. E. Impact of $\mathrm{CO}_{2}$-induced warming on simulated hurricane intensity and precipitation: Sensitivity to the choice of climate model and convective parameterization. J. Clim. 17, 3477-3495 (2004).

21. Bengtsson, L. et al. How may tropical cyclones change in a warmer climate. Tellus A $\mathbf{5 9}$, 539-561 (2007).

22. Knutson, T. R. \& Tuleya, R. E. in Climate Extremes Society (eds Diaz, H. \& Murnane, R.) (Cambridge Univ. Press, New York, in the press).

23. Lonfat, M., Marks, F. D. Jr \& Chen, S. S. Precipitation distribution in tropical cyclones using the Tropical Rainfall Measuring Mission (TRMM) microwave imager: A global perspective. Mon. Weath Rev. 132, 1645-1660 (2004).
24. Emanuel, K., Sundararajan, R. \& Williams, J. Hurricanes and global warming: Results from downscaling IPCC AR4 simulations. Bull. Am. Meteorol. Soc. 89, 347-367.

25. Zhang, R. \& Delworth, T. L. Impact of Atlantic multidecadal oscillations on India/Sahel rainfall and Atlantic hurricanes. Geophys. Res. Lett. 33, L17712 (2006).

26. Latif, M., Keenlyside, N. \& Bader, J. Tropical sea surface temperature, vertical wind shear, and hurricane development. Geophys. Res. Lett. 34, L01710 (2007).

27. Shen, W., Tuleya, R.E. \& Ginis, I. A sensitivity study of the thermodynamic environment on GFDL model hurricane intensity: Implications for global warming. J. Clim. 13, 109-121 (2000).

28. Tang, B. H. \& Neelin, J. D. ENSO Influence on Atlantic hurricanes via tropospheric warming. Geophys. Res. Lett. 31, L24204 (2004).

29. Vecchi, G. A. \& Soden, B. J. Effect of remote sea surface temperature change on tropical cyclone potential intensity. Nature 450, 1066-1070 (2007).

30. Swanson, K. Nonlocality of Atlantic tropical cyclone intensities. Geochem. Geophys. Geosys. 9 , Q04V01 (2008).

Supplementary Information accompanies this paper on www.nature.com/naturegeoscience.

Acknowledgements

We thank the WCRP CMIP3 modelling groups for contributing their model runs, and PCMDI and the IPCC Data Archive at LLNL/DOE for providing ready access to the model data. We thank I. Orlanski, B. Gross, O. Pauluis, S. Malyshev, C. Kerr and A. Leetmaa for advice and assistance. This work was partially supported by NOAA/OGP and the NASA Columbia Supercomputing Project.

\section{Author information}

Reprints and permission information is available online at http://npg.nature.com/reprintsandpermissions. Correspondence and requests for materials should be addressed to T.R.K. 
Simulated reduction in Atlantic hurricane frequency under twenty-first-century warming conditions

THOMAS R. KNUTSON, JOSEPH J. SIRUTIS, STEPHEN T. GARNER, GABRIEL A. VECCHI AND ISAAC M. HELD

Nature Geoscience 1, 359-364 (2008)

In Figure 2, a,c,e show inactive years and b,d,f show active years, rather than the other way round as was stated in the caption. 